\title{
VERIFICATION OF FLOOR PLANARITY BY TRIGONOMETRICAL MEASUREMENT OF HEIGHTS ON A 5-STOREY MONOLITHIC BUILDING
}

\author{
Štefan RÁKAY, Slavomír LABANT ${ }^{*}$, Karol BARTOŠ \\ Institute of Geodesy, Cartography and GIS, BERG Faculty, Technical University of Košice Letná 9, \\ 04200 Košice, Slovak Republic
}

Received 30 February 2017; accepted 14 March 2018

\begin{abstract}
Currently, trigonometric levelling is becoming increasingly widespread, mainly due to the increase in accuracy of stations that can measure angles with seconds and distances with submillimetre accuracy. The paper deals with the analysis of the sources of errors affecting the accuracy of results. It also describes a design of observational methodology that excludes or significantly reduces the impact of systematic errors or other errors occurring during the measurements process, in order to achieve the highest accuracy of the determined height difference. Therefore, under certain conditions, it is possible to achieve the accuracy of determining a height difference of up to $0.10 \mathrm{~mm}$ using this method. Furthermore, by the practical example, the description of the use of trigonometric levelling from the centre when verifying the floor planarity of a 5-storey monolithic building is also presented in the paper. The skeletal structure made of concrete floors supported by beams is the main structural element of the building. The finished floors showed visible deformations. Therefore, before the continuation of further construction, the control height measurement of all above-ground floors was necessary in order to ensure the safety in terms of stability and subsequent correction of the project. The resulting floor planarity is graphically visualised and analysed.
\end{abstract}

Keywords: trigonometric levelling, propagation of covariances, accuracy analysis, floor planarity, colour hypsometry, cross-sections.

\section{Introduction}

In engineering works, the determination of height differences between points or the determination of heights of points in national or local vertical datums is required very often. These measurements are required for residential, administrative or industrial buildings, waterworks, or various line constructions like motorways, railways, sewers and pipelines. Height differences (differences in elevation) between points can be determined by several methods. Their selection depends mainly on the required accuracy and available instruments. Measurements of heights (or levelling) can be divided into geometrical, trigonometric, hydrostatic, barometric and GNSS levelling. Geometrical levelling from the centre between the rods is the most accurate, while GNSS levelling is preferable to use over long distances. Hydrostatic or barometric levelling is exceptional. Trigonometric and GNSS levelling are independent of the studied terrain (see El-Ashmawy, 2014, 2017). However, the trigonometric levelling can also be used for the establishment of micro networks in production halls (see Pospíšilová, Pospíšil, \& Staňková, 2012). Trigonometric levelling is mostly used for measurement of heights of points that have a significantly different heights, or points that are located in hardly accessible places, where the use of geometrical levelling would be uneconomical (see Ceylan, Inal, \& Sanlioglu, 2005; El-Ashmawy, 2017; Z. Zhang, K. Zhang, Deng, \& Luo, 2005; Zhou \& Sun, 2013).

\section{Trigonometric determination of height}

By trigonometrical measurement, the height difference between two points is determined by an instrument (for example total station) levelled and centred on the point 1 (Figure 1) and reflectional system (for example a stake with a surveying prism) placed on the point 2.

Based on the measurement of the instrument height $h_{i}$, target height $h_{t}$ and height difference determined trigonometrically $\Delta h_{12}$ based on the measured slope distance $D$ and zenithal distance $z$, the value of the height difference $\Delta H_{12}$ can be determined according to (1) as:

$$
\Delta H_{12}=h_{i}+\Delta h_{12}-h_{t}=h_{i}+D \cdot \cos z-h_{t} .
$$

*Corresponding author. E-mail: slavomir.labant@tuke.sk 


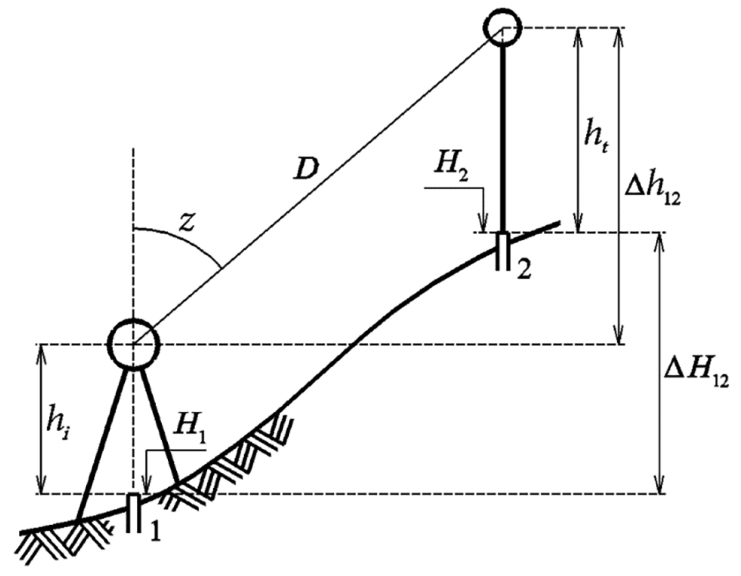

Figure 1. Trigonometric determination of height difference

In general, the height difference $\Delta h_{i j}$ is affected by the curvature of the Earth's surface, which is determined by a mathematical relationship and subsequently added to the height difference, and is dependent on the Earth's radius $R_{m}=6378000 \mathrm{~m}$ (see Ceylan et al., 2005):

$$
\Delta h_{i j E}=\left(D^{2} \cdot \sin ^{2} z\right) / 2 R_{m} .
$$

However, the curvature of the Earth's surface can be neglected for short distances (Table 1).

Table 1. Curvature of the Earth's surface depending on the length of the sight line

\begin{tabular}{|l|c|c|c|c|c|c|}
\hline $\begin{array}{l}\text { Zenithal distance } \\
\text { of a steep sight } \\
\text { line } z \text { [gon] }\end{array}$ & \multicolumn{7}{|c|}{60} \\
\hline $\begin{array}{l}\text { Length of a sight } \\
\text { line } D[\mathrm{~m}]\end{array}$ & 10 & 25 & 50 & 75 & 100 & 200 \\
\hline $\begin{array}{l}\text { Curvature of the } \\
\text { Earth's surface } \\
\Delta h_{i j E}[\mathrm{~mm}]\end{array}$ & 0.01 & 0.04 & 0.16 & 0.35 & 0.63 & 2.54 \\
\hline
\end{tabular}

Also, the vertical refraction $\mathrm{d} z$ and the deviation of normal from the plumb line $\varepsilon$ determined according to the following equation, which is subtracted from the height difference (see Ceylan et al., 2005), affects the height difference $\Delta h_{i j}$ :

$$
\Delta h_{i j V}=-D(\varepsilon+\mathrm{d} z) \sin z
$$

The issue of elimination of vertical as well as horizontal refraction is solved in Gašinec and Gašincová (2009), Sokol and Bajtala (2014), Bajtala, Sokol, and Černota (2016). Since both parameters located in brackets are unknown parameters with very small values, this equation can be neglected for short slope distances.

If the height of the point $H_{1}$ is known, then the height of the point $\mathrm{H}_{2}$ can be calculated as:

$$
\begin{aligned}
& H_{2}=H_{1}+\Delta H_{12}=H_{1}+h_{i}+\Delta h_{12}-h_{t}= \\
& H_{1}+h_{i}+D \cdot \cos z-h_{t} .
\end{aligned}
$$

The mean error of the height of the point $2-\left(\sigma_{H_{2}}\right)$ determined trigonometrically is calculated by applying the law of accumulation of covariances with partial derivations of the function of the height $\mathrm{H}_{2}$ according to the measured variables as (see Vykutil, 1983; Böhm, Radouch, \& Hampacher, 1990):

$$
\begin{aligned}
& \sigma_{H_{2}}^{2}=\left(\frac{\partial H_{2}}{\partial H_{1}}\right)^{2} \cdot \sigma_{H_{1}}^{2}+\left(\frac{\partial H_{2}}{\partial h_{i}}\right)^{2} \cdot \sigma_{h_{i}}^{2}+\left(\frac{\partial H_{2}}{\partial D}\right)^{2} \cdot \sigma_{D}^{2}+ \\
& \left(\frac{\partial H_{2}}{\partial z}\right)^{2} \cdot \sigma_{z}^{2}+\left(\frac{\partial H_{2}}{\partial h_{t}}\right)^{2} \cdot \sigma_{h_{t}}^{2} \cdot
\end{aligned}
$$

where: $\sigma_{H_{1}}-$ accuracy (standard deviation) of determining the point $H_{1}$ height; $\sigma_{h_{i}}$ - accuracy (standard deviation) of determining the height of the instrument;

$\sigma_{D}$ - accuracy (standard deviation) of determining the slope distance; $\sigma_{z}$ - accuracy (standard deviation) of determining the zenithal distance; $\sigma_{h_{t}}$ - accuracy (standard deviation) of determining the height of the reflectional system.

Since the measurement is realised from a one survey station and with unchanged heights of instrument and target point, the equation (5) can be simplified to:

$$
\sigma_{H_{2}}^{2}=\left(\frac{\partial H_{2}}{\partial D}\right)^{2} \cdot \sigma_{D}^{2}+\left(\frac{\partial H_{2}}{\partial z}\right)^{2} \cdot \sigma_{z}^{2} .
$$

which, after modification, represents the accuracy of determining the height difference:

$$
\sigma_{H_{2}}^{2}=\left(\cos ^{2} z\right) \cdot \sigma_{D}^{2}+D^{2} \cdot\left(\sin ^{2} z\right) \cdot\left(\frac{\sigma_{z}}{\rho^{m g o n}}\right)^{2} .
$$

where: $\rho^{m g o n}$ - conversion factor; $\rho^{m g o n}=200^{g o n} / \pi=$ $63,661.98^{m g o n}$.

In general, the accuracy of determining the height difference $\Delta h$ (the mean error $\sigma_{\Delta h}^{2}$ ) depends on, among other things (errors of observation, random errors, systematic errors), the accuracy of measurement of determining variables (see Dušek \& Skořepa, 2010), i.e. the accuracy of measurement of distance $D$ and zenithal distance $z$. For short and steep sight lines, where the zenithal distance $z$ converges to the value of $0{ }^{g o n}$, mainly the mean error of the measured length is reflected in the accuracy of determining the height difference. In the case of sight lines close to the horizontal plane of an instrument $(z$ converges to the value of $100 \mathrm{gon}$ ) mainly the mean error of determining the zenithal distance is reflected in the accuracy of determining the height difference (Figure 2, Table 2, Figure 3).

As follows from numerical values in Table 1 and Figure 3, the error of determining the height difference $\sigma_{\Delta h}$ depends on, to a different extent, size of determining variables and the accuracy of their measurement. For $z=100^{\text {gon }}$, the $\sigma_{\Delta h}$ increases only slowly with increasing length, since only the mean error of measured zenithal distances is reflected into the result. By decreasing the 


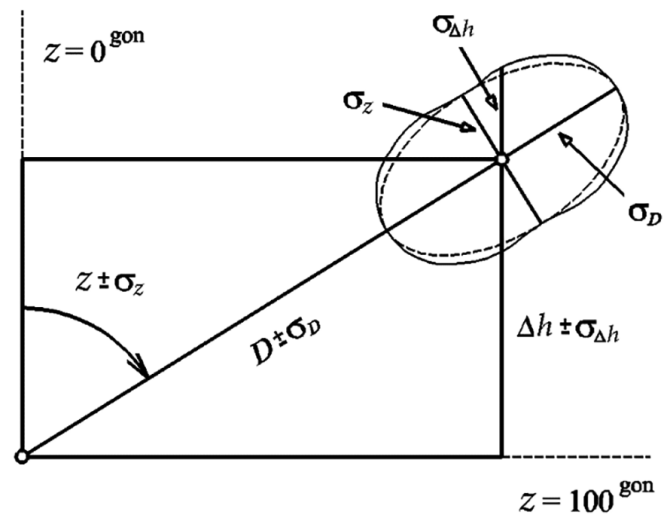

Figure 2. A general illustration of the mean error $\sigma_{\Delta h}$ of determining the height difference $\Delta h$ by the trigonometrical method, depending on the accuracy of determining slope distances $D$ and zenithal distances $z$

Table 2. The values of accuracy of determining the height difference correspond to measurements by the Leica Viva TS15 instrument $\left(\sigma_{D}=1 \mathrm{~mm}+1.5 \mathrm{ppm} \cdot D, \sigma_{z}=0.3^{\text {mgon }}\right)$

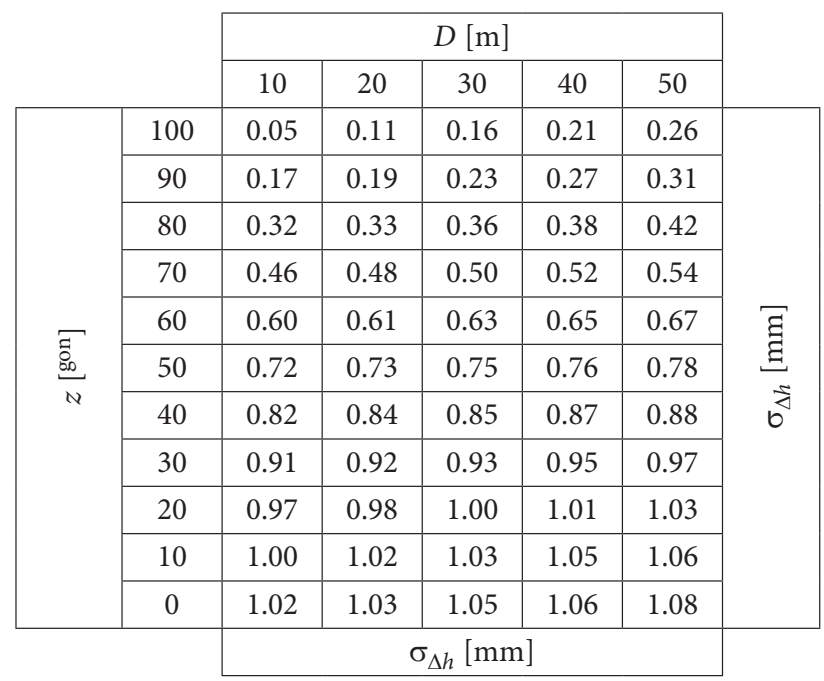

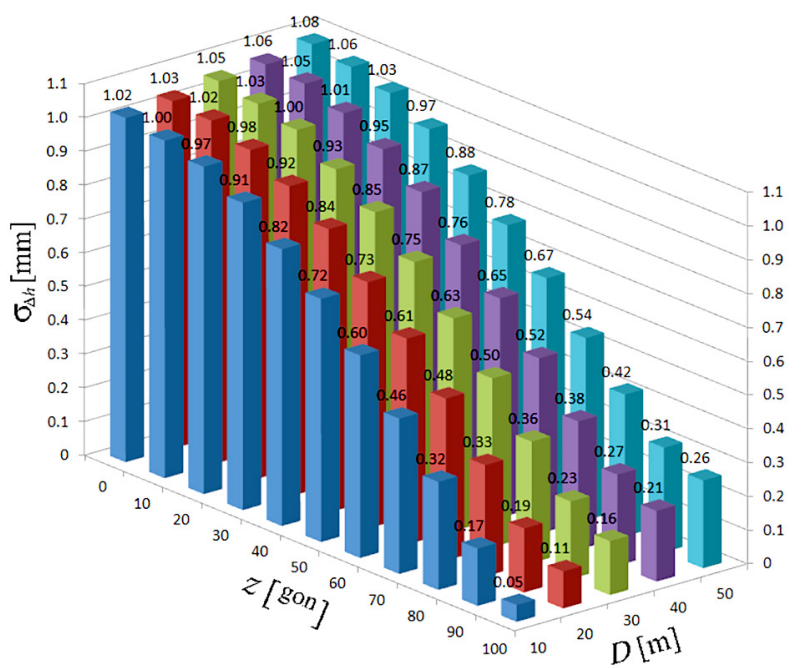

Figure 3. Graphical illustration of the accuracy $\sigma_{\Delta h}$ of determining the height difference $\Delta h$ by the Leica Viva TS15 instrument zenithal distance, the error of distance meter affects the result more and more. A more detailed analysis of this issue is given in Dušek and Skořepa (2010).

\section{Trigonometric levelling}

A small mean error in the measurement of distances by distance meters and the current accuracy of measurement of vertical angles by modern instruments with second's accuracy, equipped with an automatic index of the vertical circle, change the importance of trigonometric levelling in terms of quality.

Furthermore, by using the methodology of trigonometric levelling from the centre, the error of determining the height of the instrument $\sigma_{h_{i}}$ is eliminated. At the same time, also the error of determining the height of the reflectional system $\sigma_{h_{t}}$ is excluded from results by subtracting backsights and foresights (at unchanged height $h_{t}=$ const) (Figure 4$)$.

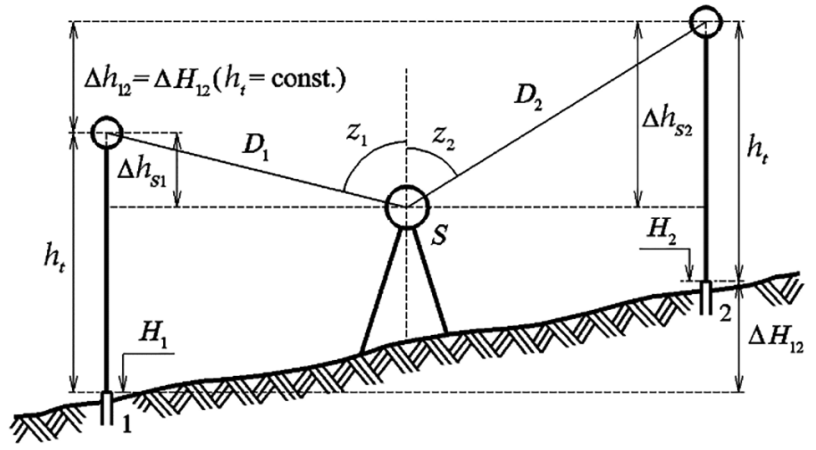

Figure 4. Trigonometric levelling from the centre

Therefore, the height difference between two points in a levelling system can be calculated as the difference of foresight and backsight trigonometric differences in elevation:

$$
\Delta H_{12}=\Delta h_{12}=\Delta h_{S 1}-\Delta h_{S 2}=D_{1} \cdot \cos z_{1}-D_{2} \cdot \cos z_{2} .
$$

The mean error of height difference $\sigma_{\Delta H_{12}}^{2}$ between points No. 1 and 2 is calculated by the application of propagation of errors as the sum of mean errors of determining height differences by the trigonometric method according to:

$$
\begin{aligned}
& \sigma_{\Delta H_{12}}^{2}=\left(\frac{\partial \Delta H_{12}}{\partial D_{1}}\right)^{2} \cdot \sigma_{D}^{2}+\left(\frac{\partial \Delta H_{12}}{\partial z_{1}}\right)^{2} \cdot \sigma_{z}^{2}+ \\
& \left(\frac{\partial \Delta H_{12}}{\partial D_{2}}\right)^{2} \cdot \sigma_{D}^{2}+\left(\frac{\partial \Delta H_{12}}{\partial z_{2}}\right)^{2} \cdot \sigma_{z}^{2} .
\end{aligned}
$$

\section{The survey of floors height of a building under construction}

A practical solution of the given issue was the use of the method of trigonometric levelling from the centre to determine the height of 4 above ground floors of the 
building under construction (Figure 5). The supporting part of the building was constructed of a concrete skeletal structure. The reason for this survey were visible deformations (bending, bulges) at individual floors, representing a restraint to further continuation of construction and requiring corrections of the original project.

The Leica Viva TS15 instrument with a surveying prism was used to measure height differences (Figure 6 on the left). Dimensions of the ground plan of the building are approximately $20 \times 58 \mathrm{~m}$ with the height of the top floor $13.630 \mathrm{~m}$. On each floor, the height of the instrument's horizon was determined as an average value

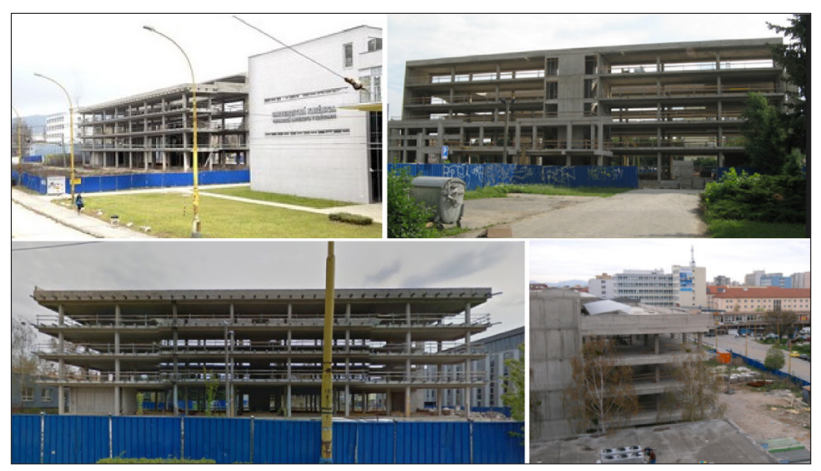

Figure 5. The 5-storey building under construction

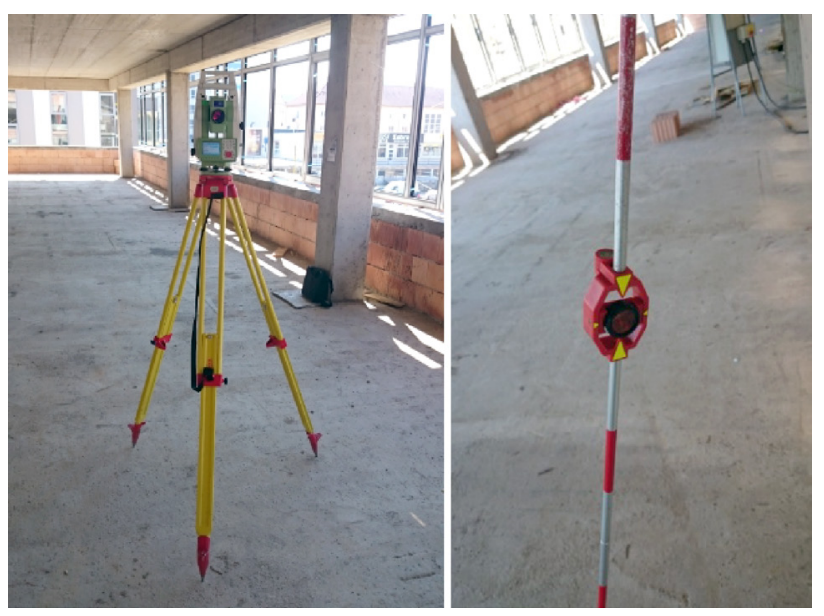

Figure 6. Leica Viva TS15 ${ }^{\text {nd }}$ Leica GMP111 with a stake of three height differences measured to the points of the setting-out network located in the vicinity of the structure of about 50-60 m.

Heights of points of the setting-out network were given with an accuracy of 3 decimal places of the meter. Mean errors of determining the height of an instrument's horizon on the individual floors are given in Table 3.

About 160 points were measured on each aboveground-level (AGL) floor. All height differences were measured using the function of automatic tracking "lock target". By using this function, the size of the error of point targeting was decreased, and the speed and effectiveness of the measurement were increased.

Table 3. Accuracy of relative height determination

\begin{tabular}{|c|c|c|}
\hline Floor No. & $\begin{array}{c}\text { Height of } \\
\text { instrument's } \\
\text { horizon }[\mathrm{m}]\end{array}$ & $\begin{array}{c}\text { Accuracy of its } \\
\text { determination } \\
{[\mathrm{mm}]}\end{array}$ \\
\hline 2. AGL & 4.452 & 1.5 \\
\hline 3. AGL & 8.714 & 0.0 \\
\hline 4. AGL & 11.965 & 1.0 \\
\hline 5. AGL & 15.201 & 1.5 \\
\hline
\end{tabular}

During the whole measurement, the height of the reflectional system was set to a constant value of $1.6 \mathrm{~m}$, corresponding to the instrument's height, in order to minimise the influence of the error of distance meter on results, which is several times higher as the error of measuring zenithal distance at such short distances. Although each floor was vertically determined in relation to the points of the setting-out network as a whole with the error given in Table 1, it is possible to determine height differences of detailed survey points on the floor at the given dimensions of the building with an accuracy of $0.10 \mathrm{~mm}$ by this method of measurement (Figure 2). The height course of concrete floors was evaluated on the basis of measured height differences at the locations identified by the project engineer by red crosses (marks), whose layout was the same on all floors (Figure 7 - the floor plan of the $2^{\text {nd }}$ above-ground level floor).

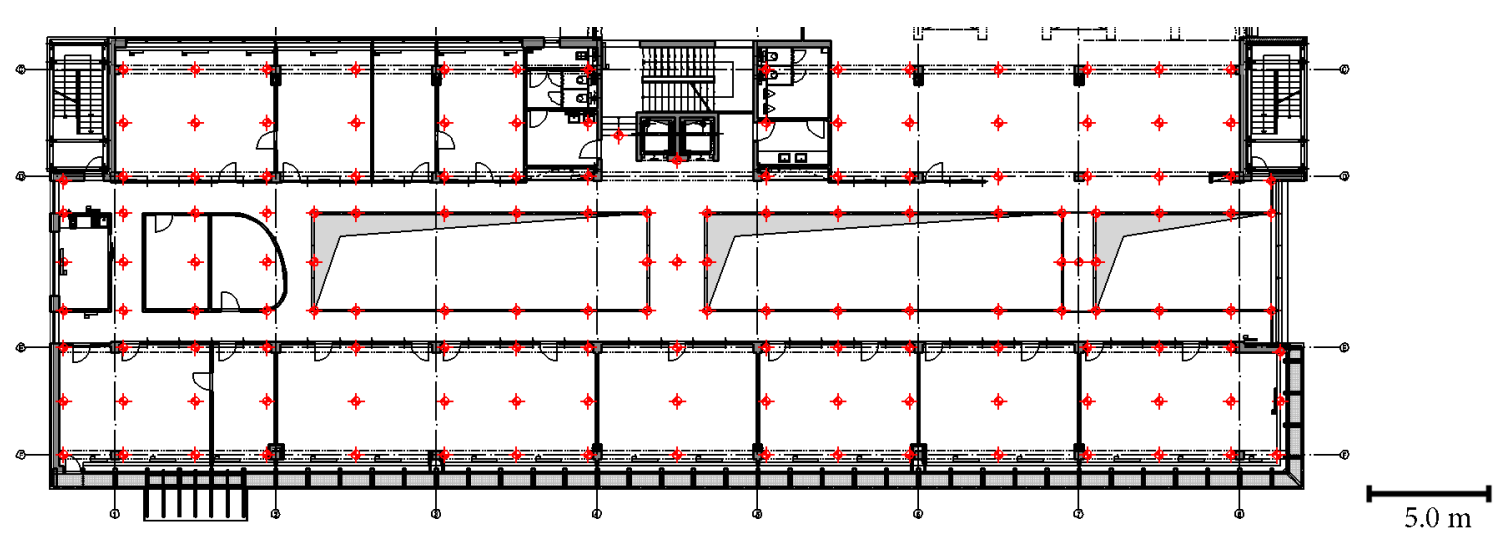

Figure 7. The layout of measured detailed survey points on the $2^{\text {nd }}$ AGL floor 
The non-flatness (non-horizontality) of floors has an impact on further unpredictable construction works, which affect the economics. This is, in particular, an increase in the cost of building modifications. The overall economic efficiency of building modifications can be solved using the Data Envelopment Analysis (DEA) method, which determines the effectiveness of unpredictable modifications (Drabiková, 2016).

\section{Processing, visualisation and analysis of the results}

After the completion of measurements on all floors, the processing of measurements and subsequent graphical visualisation were processed. The creation of a contour model (Figure 8), which represents places with the same height by means of isolines, is one of the basic options. The contours were removed in the places of the missing floor. According to the contour model, it is evident that the largest deformations (in this case bending) were confirmed in the centre of the building on the upper bridge, where is the highest density of contours and at the same time the lowest point of the whole floor.

Also, 2 longitudinal and 3 vertical cross sections of individual floors were generated from the final model. The layout of each section is the same on all floors. Their positional layout on the $2^{\text {nd }}$ AGL floor is shown in Figure 9.

Two longitudinal and three vertical cross sections (Figure 10) graphically illustrates the non-horizontality of the $2^{\text {nd }}$ floor of this monolithic building. The projected height of the $2^{\text {nd }}$ floor is $3.880 \mathrm{~m}$.

According to the course of these longitudinal and vertical cross sections, it is evident that the floor satisfies the projected height in the longitudinal section $\mathrm{A}-\mathrm{A}^{\prime}$ at the edges of the floor, but it is deflected towards the centre. Other vertical sections have various course, but mostly, it is below the projected height of the given floor.

By colour hypsometry, elevation models of individual above ground level floors, where heights globally vary from $-6 \mathrm{~cm}$ to $+3 \mathrm{~cm}$, were created. The colour hypsometry was chosen so that the projected height was still represented by a red colour on all floors. The created model (Figure 11) represents the $2^{\text {nd }}$ floor and illustrates the vertical course of the concrete surface of the floor created by interpolation between spot heights of measured detailed survey points. The height differences of the real floor range from $+3.820 \mathrm{~m}$ to $+3.890 \mathrm{~m}$, where the projected height given by the project as $+3.880 \mathrm{~m}$ is shown in red.

The highest changes in elevation can be found at the top right part of the floor (Figure 11) and on the upper

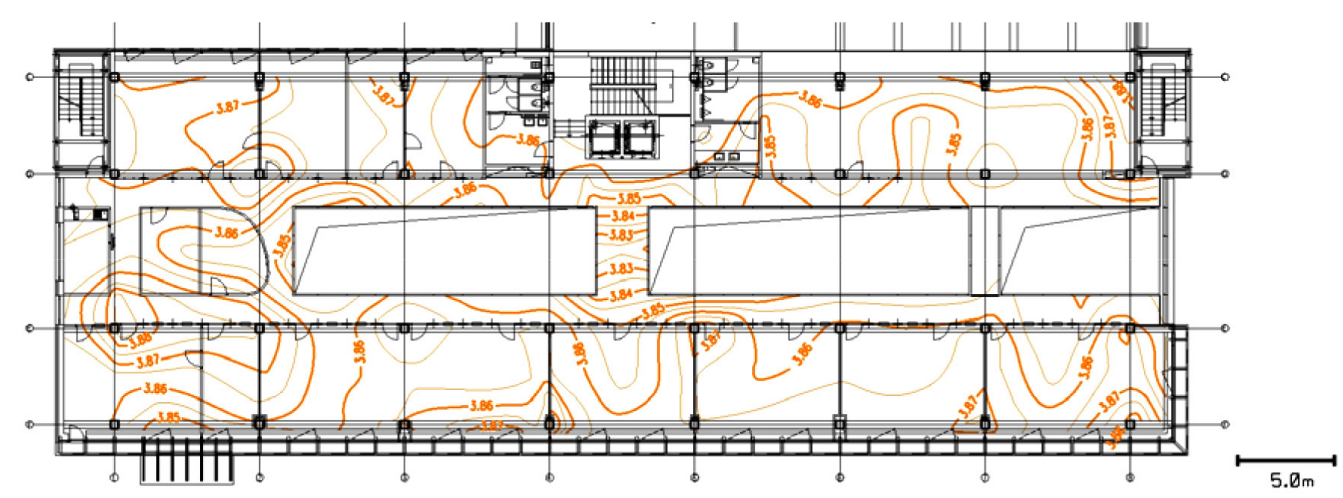

Figure 8 . The contour height model of the $2^{\text {nd }}$ AGL floor

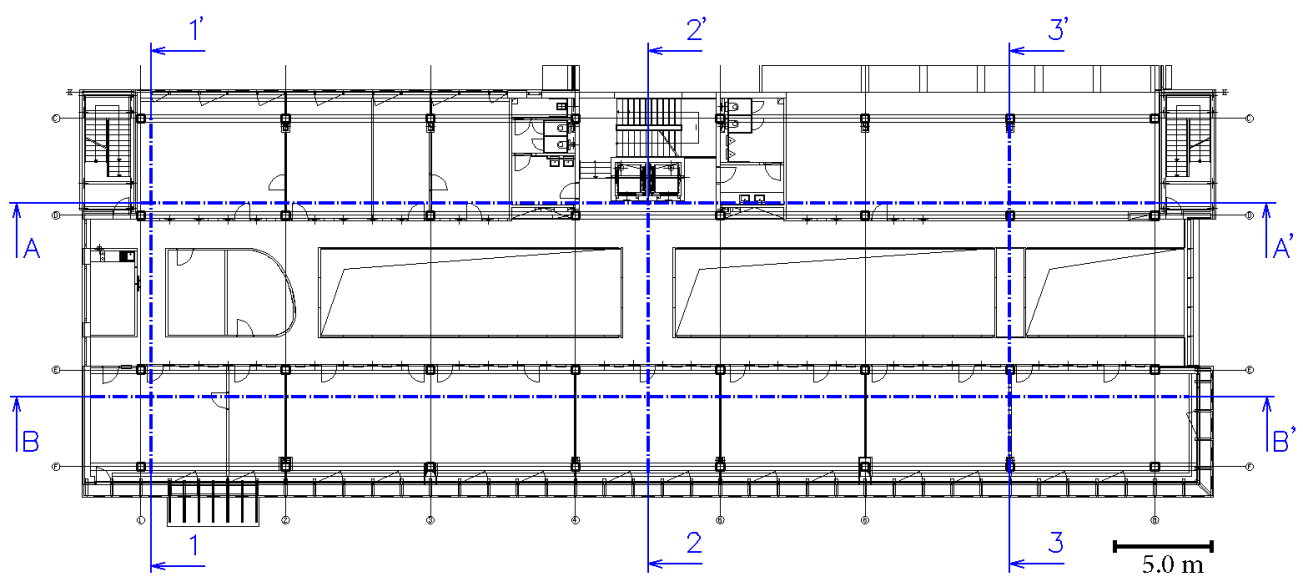

Figure 9. Positional layout of longitudinal and vertical cross sections of the $2^{\text {nd }}$ AGL floor 

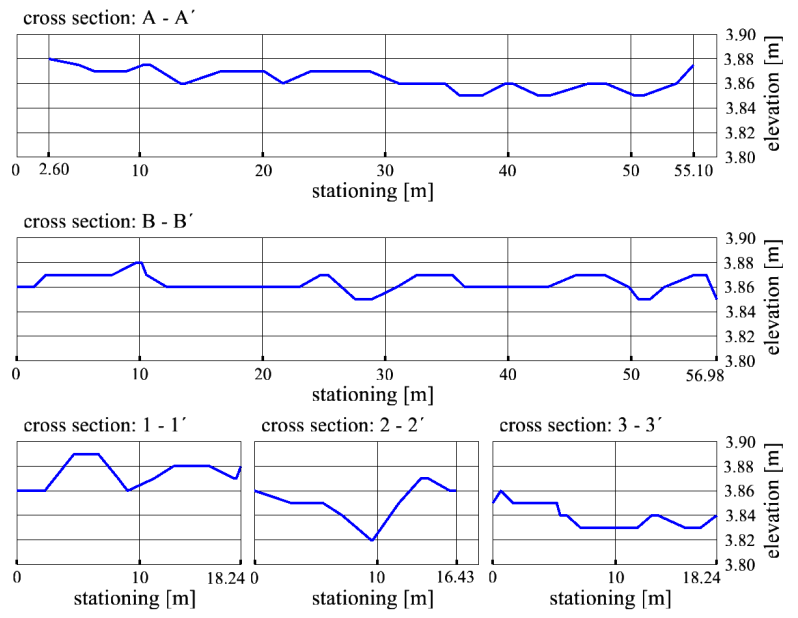

Figure 10. The vertical course of longitudinal and vertical cross sections of the $2^{\text {nd }}$ AGL floor bridge in the central part. Most of the floor has a green colour, representing the floor height of $3.850 \mathrm{~m}, 3$ centimetres lower than the projected height.

When evaluating height differences on the $3^{\text {rd }}$ floor, where the projected height is given by the project as $+7.130 \mathrm{~m}$ and marked in red, variations in the height of the real floor range from $+7.090 \mathrm{~m}$ to $+7.160 \mathrm{~m}$.

The highest depressions compared to the project are located mainly along the entire central part, i.e. near skylights and on the connecting footbridges (Figure 12). Conversely, the highest bulges and elevations are located at the bottom and left upper part, i.e. areas marked with a purple colour (Figure 12). The top right part of the floor is about $3 \mathrm{~cm}$ below the projected height.

The projected height of the $4^{\text {th }}$ AGL floor with the height of $+10.380 \mathrm{~m}$ is shown in red (Figure 13) and the vertical course of the real floor ranges between $+10.330 \mathrm{~m}$ to $+10.390 \mathrm{~m}$.

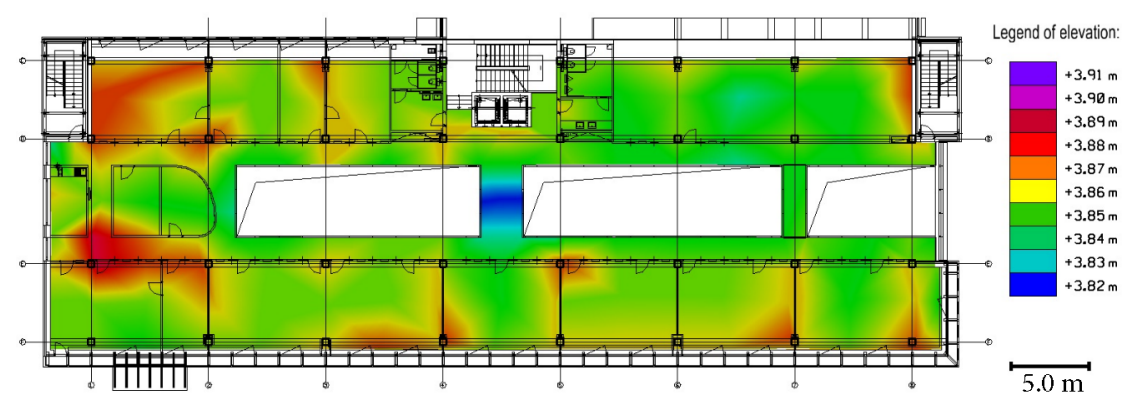

Figure 11 . The colour hypsometry model of the $2^{\text {nd }}$ AGL floor with the legend of height conditions

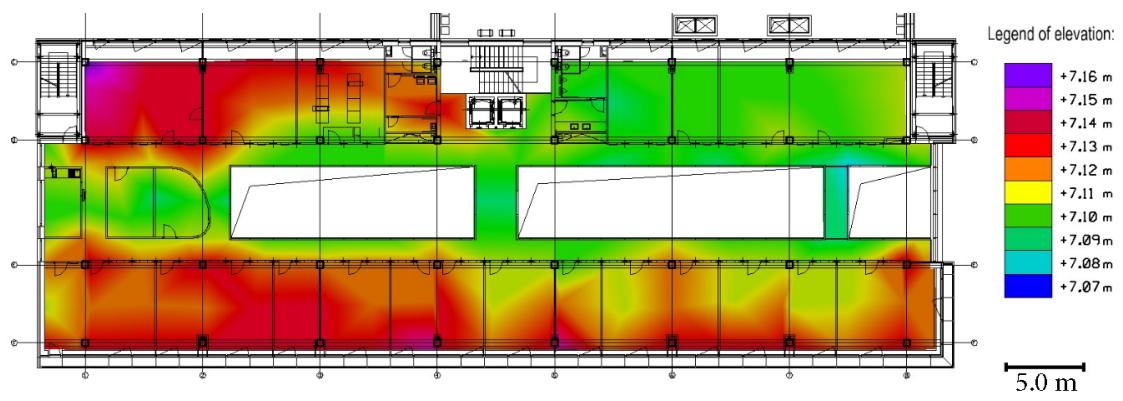

Figure 12. The colour hypsometry model of the $3^{\text {rd }}$ AGL floor with the legend of height conditions

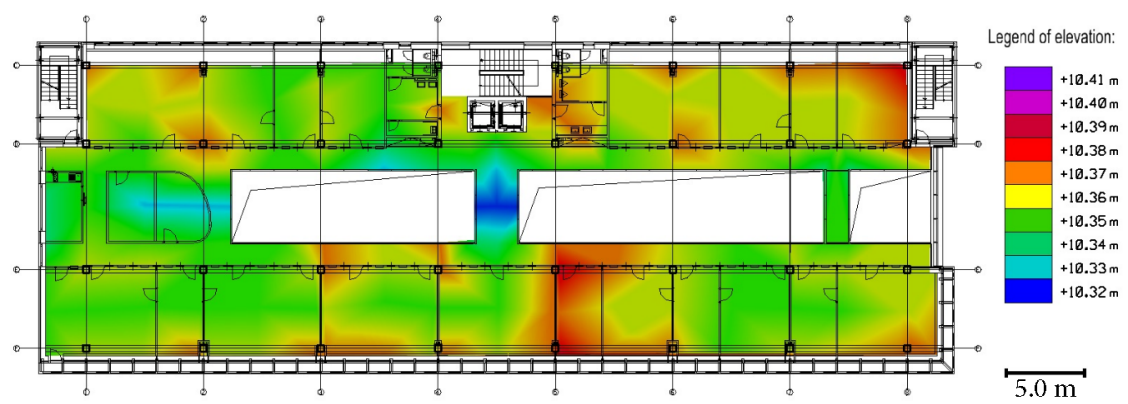

Figure 13. The colour hypsometry model of the $4^{\text {th }}$ AGL floor with the legend of height conditions 


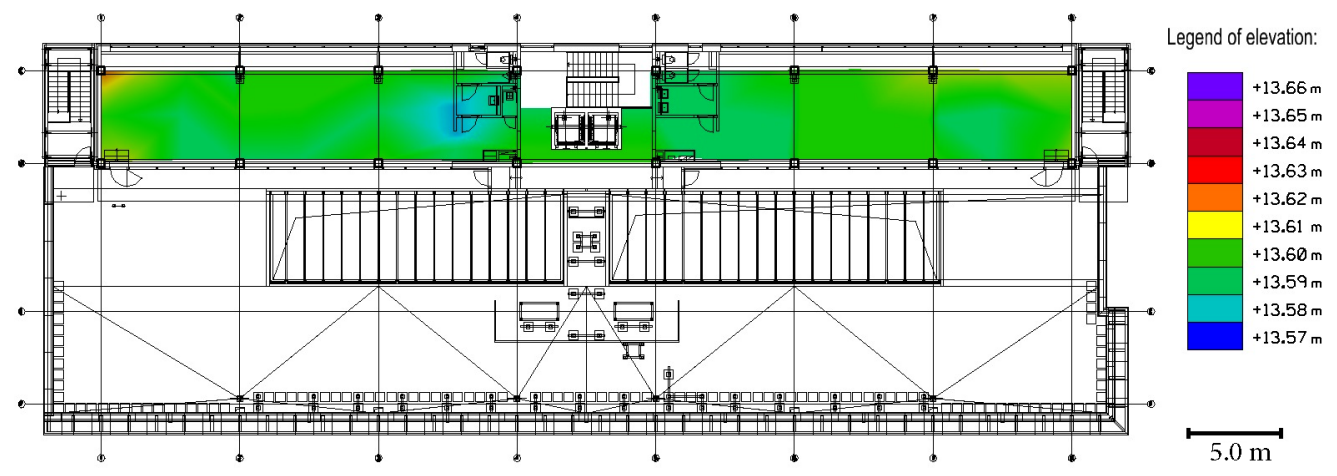

Figure 14. The colour hypsometry model of the $4^{\text {th }}$ AGL floor with the legend of height conditions

This floor can be characterised by the largest local deformations and sharp changes in height. The highest gradient is at the distance of about $5 \mathrm{~m}$ from the bottom red part towards the connecting footbridge in the central part of the $4^{\text {th }}$ AGL floor of the building (Figure 13).

The $5^{\text {th }}$ AGL floor has a relatively balanced elevation course ranging from $+13.590 \mathrm{~m}$ to $13.630 \mathrm{~m}$. The projected height $+13.630 \mathrm{~m}$ is shown in red (Figure 14).

Mostly, the green colour prevails on the hypsometric model (Figure 14), representing the height of the floor $3 \mathrm{~cm}$ below the projected height. The projected height was only observed in the top left corner.

\section{Conclusions}

Significant differences in the comparison of results from trigonometrical measurement of heights and geometrical levelling can result from the accumulation of effects of random errors, incomplete elimination of systematic errors and neglect, or only partial elimination, of errors resulting from physical properties of the environment (refraction, deflection of the vertical, etc.). Therefore, the trigonometrical measurement of heights is limited to relatively short distances. Hence, to achieve the best results, it is important to follow several principles when realising trigonometric levelling:

Select short sight lines when measuring. Lengthening of sight lines leads to the tendency to increase random errors due to the unpredictability of the physical environment. It can be either the unfamiliarity with the air temperature over the entire measured length and related corrections of the measured length, as well as the variable refractive coefficient, which is only estimated during the application of corrections $(\mathrm{k}=0.13$ - the average value (see Jordan, Eggert, \& Kneissl, 1956)).

Select equal lengths of sight lines. If conditions allow, it is necessary to ensure in the levelling system that the length of the backsight is approximately the same as the foresight (the influence of refraction and curvature of the Earth are excluded).

Use the same height of the reflectional system when measuring one levelling system (excluding an error from the uncertainty of determining the height of the reflectional system).
Set the height of the reflectional system according to the height of instrument's horizon. This condition is significant only when measuring in a flat area when the size of zenithal distances close to $z=100$ gon significantly increases the accuracy of measurement of heights.

Although the results from trigonometric levelling can hardly be compared with the results from geometric levelling, under certain conditions and compliance with the above principles, the geometric levelling can be successfully replaced by trigonometric levelling and achieve the same, or even higher, accuracy.

\section{References}

Bajtala, M., Sokol, Š., \& Černota, P. (2016). Estimation of a horizontal refraction in a geodetic network. Journal of the Polish Mineral Engineering Society, 37(1), 201-212. Retrieved from http://www.potopk.com.pl/Full_text/2016_full/IM\%20 1-2016-a30.pdf

Böhm, J., Radouch, V., \& Hampacher, M. (1990). Teorie chyb a vyrovnávací počet [Theory of errors and adjustment computations]. Geodetický a kartografický podnik Praha (in Czech).

Ceylan, A., Inal, C., \& Sanlioglu, I. (2005, April 16-21). Modern height determination techniques and comparison of accuracies. From Pharaohs to Geoinformatics, FIG Working Week 2005 and GSDI-8. Cairo, Egypt. Retrieved from https://www. fig.net/resources/proceedings/fig_proceedings/cairo/papers/ ts_33/ts33_05_ceylan_etal.pdf

Drabiková, E. (2016). Quantitative method DEA for economic analysis of efficiency. Engineering education in the $21^{\text {st }}$ century (pp. 35-38). Košice, TU. ISBN 978-80-553-2570-5.

Dušek, R., \& Skořepa, Z. (2010). Střední chyba ve všech směrech [Mean error in all directions]. Geodetický a kartografický obzor, 56(1), 12-17. Praha (in Czech). Retrieved from http:// archivnimapy.cuzk.cz/zemvest/cisla/Rok201001.pdf

El-Ashmawy, K. (2014). Accuracy, time cost and terrain independence comparisons of levelling techniques. Geodesy and Cartography, 40(3), 133-141. https://doi.org/10.3846/20296991.2014.962727

El-Ashmawy, K. (2017). Developing and testing a method for deformations measurements of structures. Geodesy and Cartography, 43(1), 35-40.

https://doi.org/10.3846/20296991.2017.1305545

Gašinec, J., \& Gašincová, S. (2009). Estimation vertical components of refraction from terrestrial and satellite geodetic measuring. Acta Montanistica Slovaca, 14 (Special 1), 4753. Retrieved from https://actamont.tuke.sk/pdf/2009/ s1/8gasinec.pdf 
Jordan, W., Eggert, O., \& Kneissl M. (1956). Handbuch der Vermessungskunde Band 3 - Höhenmessung - Tachymetrie. Stuttgart, Metzler.

Pospíšilová, L., Pospíšil, J., \& Staňková, H. (2012). Micro-network creation in industrial surveying. Geodesy and Cartography, 38(2), 70-74.

https://doi.org/10.3846/20296991.2012.692216

Sokol, Š., \& Bajtala, M. (2014). The elimination of vertical refraction in trigonometric measurements of height differences. Acta Montanistica Slovaca, 19(2), 90-94. Retrieved from https://actamont.tuke.sk/pdf/2014/n2/6Sokol.pdf
Vykutil, J. (1983). Teorie chyb a vyrovnávací počet [Theory of errors and adjustment computations]. Ediční středisko VUT, Brno (in Czech).

Zhang, Z., Zhang, K., Deng, Y., \& Luo, Ch. (2005). Research on precise trigonometric leveling in place of first order leveling. Geo-spatial Information Science, 8(4), 235-239. https://doi.org/10.1007/BF02838654

Zhou, X., \& Sun, M. (2013). Study on accuracy measure of trigonometric leveling. Applied Mechanics and Materials, 329, 373377.

https://doi.org/10.4028/www.scientific.net/AMM.329.373 